Article

http://dergipark.gov.tr/ataunizfd

\title{
Portakalda Antraknoz Hastalığı Etmeni Colletotrichum gloeosporioides'in Biyolojik Mücadele İmkanlarının Araştırılması
}

\author{
Nasibe TEKINER* (iD Elif TOZLU (iD) Recep KOTAN \\ Atatürk Üniversitesi, Ziraat Fakültesi, Bitki Koruma Bölümü, Erzurum, Türkiye \\ (*Sorumlu yazar e-mail: nasibe.tekiner@ atauni.edu.tr) \\ DOI: 10.17097/ataunizfd.544964 \\ Geliş Tarihi (Received Date): 26.03.2019 \\ Kabul Tarihi (Accepted Date): 05.06.2019
}

\begin{abstract}
ÖZ: Fungisitlerin insan ve çevre sağlığını olumsuz etkilemesi, hastalık etmenlerinin fungisitlere karşı direnç oluşturması ve tarımsal ürünlerdeki kalıntı sorunu kimyasal mücadeleye alternatif yöntemlerden olan biyolojik mücadelenin önemini bir kat daha artırmıştır. Sebze ve meyvelerde yaygın olarak görülen antraknoz hastalığı etmeninin (Colletotrichum gloesporoides) in vitro koşullarda mikrobiyal antagonistlerle mücadele edilebilirliğinin araştırıldığı bu çalışmada toplam 9 adet biyoajan bakteri izolatı [Bacillus megaterium (TV 3D), Bacillus subtilis (TV 6F, TV 17C, CP 1), Bacillus cereus (TV 85D), Paenibacillus polymxa (TV 12E), Pantoea agglomerans (RK 79, RK 92), Pseudomonas fluorescens (MF 3)] ve 3 adet biyoajan fungus izolatı [Trichoderma harzianum (ET 4, ET 14, NT 1)] kullanılmıştır. Biyoajan fungusların patojene karşı etkililiği petri kaplarına karşılıklı konularak, bakterilerin ise merkeze patojen konulup etrafina bakteri çizilerek yapılmıstır. Uygulama sonucunda tüm mikrobiyal antagonistlerin in vitro şartlarda patojen fungusun gelişimini engellediği ve $P$. fluorescens'in MF 3 izolatının (\%69,05) ve T. harzianum'un ET 4 izolatının $(\% 82,50)$ en etkili izolatlar olduğu belirlenmiştir.
\end{abstract}

Anahtar kelimeler: Portakal, Colletotrichum gloesporoides, Pseudomonas fluorescens, Trichoderma harzianum, Biyolojik mücadele

Investigation of Biological Control Possibility of Anthracnose Disease Agent, Colletotrichum gloeosporioides, on Orange

\begin{abstract}
The negative effect of fungicides on human and environmental health, resistance to fungicides and the problem of residue in agricultural products are getting increase the importance of biological control one of the alternative methods for chemical control. Nine bioagent bacterial isolates [Bacillus megaterium (TV 3D), Bacillus subtilis (TV 6F, TV 17C, CP 1), Bacillus cereus (TV 85D), Paenibacillus polymxa (TV 12E), Pantoea agglomerans (RK 79, RK 92), Pseudomonas fluorescens (MF 3)] and three bioagent fungi isolates [Trichoderma harzianum (ET 4, ET 14, NT 1)] were used in this study the investigation of biological control of anthracnose disease (Colletotrichum gloesporoides) common in vegetables and fruits in in vitro. As a result of the application, it was determined that all microbial antagonists prevented the development of pathogen fungus in vitro and P. fluorescens MF 3 isolate $(69.05 \%)$ and T. harzianum ET 4 isolates $(82.50 \%)$ were the most effective isolates.
\end{abstract}

Keywords: Orange, Colletotrichum gloesporoides, Pseudomonas fluorescens, Trichoderma harzianum, Biological control

\section{GİRIŞ}

Portakal (Citrus sinensis L. Osb) Citrus cinsi içerisinde yer alan ülkemizin subtropik iklime sahip olan Akdeniz ve Ege Bölgeleri ile az da olsa Marmara ve Doğu Karadeniz Bölgeleri'nde yetiştiriciliği yapılan suptropik bir meyve türüdür (Akgün, 2006). 2017 yılı verilerine göre, Dünyada 637 milyon ton yaş meyve üretiminin 68,2 milyon tonunu portakal üretimi oluşturmaktadır (FAO, 2017). Portakal üretiminde önemli bir potansiyele sahip olan Türkiye, dünya üretiminde yedinci sırada yer alırken, yaş meyveler içerisinde portakal \%10,2'lik bir paya sahiptir (TÜİK, 2017). Portakal içerdiği $C$ vitamini ile insan sağlığında önemli bir yere sahip olup, taze tüketimin yanında kuru meyve, marmelat ve meyve suyu olarak gida sektöründe ve ham madde olarak kozmetik sektöründe kullanılmaktadır (Akgün, 2006).

Yaş meyve ve sebzelerin yapılarında bulunan vitamin, mineral ve organik asitlerden dolayı taze olarak tüketilmeleri zorunludur. Fakat meyve ve sebzelerde hasat, depolama ve tüketiciye kadar geçen süreçte biyotik ve abiyotik stres faktörü kaynaklı bozulmalara maruz kalırlar. (Benli, 2003). Biyotik stres faktörlerinden meydana gelen bozulmalar yaklaşık \%20-25 oranında (Singh and Sharma, 2007) olup, büyük kısmı asitçe zengin ve nemli ortamlarda geliştikleri için fungal etmenlerden kaynaklanmaktadır (Karaçalı, 1993; Benli, 2003). Hasat sonrası ve depolama sürecinde kayıplara yol açan önemli fungal hastalık etmenleri Botrytis cinerea, Alternaria alternata f. sp. citri, Penicillium digitatum, Penicillium italicum, Phytophthora citrophthora, Lasiodiplodia theobromae (Diplodia natalensis), Geotrichum citri-aurantii, Aspergillus niger, Rhizopus stolonifer ve Colletotrichum gloesporoides'dir (Aloui et al., 2014).

Antraknoz hastalığına sebep olan $C$. gloeosporioides, turunçgillerin en ciddi hastalıklarından birisidir (Zhang and Timmer, 2007). C. gloesporoides'in neden olduğu antraknoz hastalığının kontrolü için carbendazim, methyl thiofanat, benomyl, maneb, chlorothalonil ve mancozeb içeren sentetik fungisitler kullanılmaktadır (Mahoney and Tattar, 1980). Fakat fungisit kullanımının çevre kirliliği, insan sağlığının bozulması, hedef dişı organizmalar üzerindeki öldürücü etkisi, patojenlerde fungisit direncinin 
gelişmesi ve meyvelerde kalıntı oluşturması gibi olumsuzluklar nedeniyle alternatif hastalık mücadele stratejilerine ihtiyaç duyulmaktadır (Dubey et al., 2008). Meyve ve sebzelerin hasat sonrasi bozulmasının önlenmesine yönelik mikrobiyal antagonistlerin kullanımı fungisitlere alternatif mücadele yöntemlerinden bir tanesidir (Ongena and Jacques, 2008). Depo koşullarında birçok parametrenin sabit tutulabilmesi nedeni ile biyolojik mücadele çalışmaları için daha uygun ve başarılı bir ortam oluşturulmaktadır (Talibi et al., 2014). Nitekim, C. gloesporoides'in depo koşullarında biyolojik mücadelesine yönelik yapılan birçok çalışmada başarılı sonuçlar elde edilmiştir (Than et al., 2008; Yamamato et al., 2014; Zhou et al., 2016).

Bu çalışmada amaç, 9 adet bakteriyel ve 3 adet fungal mikrobiyal antagonist mikroorganizmaların depo koşullarında portakalda antraknoz hastalığına neden olan C. gloesporoides'e karşı in vitro koşullarda test edilmesidir.

\section{MATERYAL VE METOT}

Materyal

Patojen fungus, antagonistik biyoajan bakteriler ve funguslar

Marketten alınan hastalıkla bulaşık portakal meyvesi üzerinden izole edilen patojen fungus saflaştırılmış, patojenisite testi ve moleküler tanısı yapılmış ve Patates Dextroz Agar (Difco, PDAbesiyerinde $+4^{\circ} \mathrm{C}$ 'de Atatürk Üniversitesi, Ziraat Fakültesi, Bitki Koruma Bölümü Bitki Klinik Laboratuvarında muhafaza edilmiştir.

Antagonist biyoajan fungus ve bakteri olarak ise daha önce yapılan biyolojik mücadele çalışmalarında farklı hastalık etmenlerine karşı etkili olduğu belirlenen izolatlar kullanılmıştır (Çizelge 1,2).

Çizelge 1. Çalışmada Kullanılan Antagonistik Bakteri İzolatları

\begin{tabular}{llll}
\hline İzolat & $*$ MIS Tanı & Konukçu & Referans \\
\hline TV 3D & Bacillus megaterium & Çavdar & Ekinci vd., 2014 \\
TV 6F & Bacillus subtilis & Buğday & Erman vd., 2010 \\
TV 12E & Paenibacillus polymyxa & Buğday & Erman vd., 2010 \\
TV 17C & Bacillus subtilis & Ahududu & Ekinci vd., 2014 \\
TV 85D & Bacillus cereus & Şekerpancarı & Erman vd., 2010 \\
RK 79 & Pantoea agglomerans & Elma & Karakurt vd., 2010 \\
RK 92 & Pantoea agglomerans & Şeftali & Ekinci vd., 2015 \\
CP 1 & Bacillus subtilis & Ricania simulans & Tozlu vd., 2018a \\
MF 3 & Pseudomonas fluorescens & Toprak & Güneş vd., 2015 \\
\hline
\end{tabular}

*MIS: Mikrobiyal Tanı Sistemi

Çizelge 2. Çalışmada kullanılan hiperparazitik fungus izolatları

\begin{tabular}{llll}
\hline İzolat & Moleküler Tanı & Konukçu & Referans \\
\hline ET 4 & Trichoderma harzianum & At kestanesi & Tozlu vd., 2018b \\
ET 14 & Trichoderma harzianum & Sarıçam & Tozlu vd., 2018b \\
NT 1 & Trichoderma harzianum & Toprak & Tekiner vd., 2018 \\
\hline
\end{tabular}

\section{Metot}

\section{Patojenisite Testi}

Colletotrichum gloesporoides izolatının patojenisitesi portakal meyvesi üzerinde test edilmiştir. Portakal meyveleri, musluk suyu altında yıkanarak laminar flow kabin içerisinde steril filtre kağıdı üzerinde $\% 70$ ethanol ile yüzeysel sterilizasyona tabi tutulmuş, meyve üzerinde steril bistüri ile yara açılmış ve daha önceden PDA besi ortamında 5 gün geliştirilmiş olan (taze $C$. gloesporoides kültürünün kenar kısmından 6 mm'lik misel diski uygulanmıştır. Meyveler yara yüzeyinin etrafi parafilm ile sarılarak tabanına steril nemli kurutma kağıdı serilen plastik kutulara (7L) yerleştirilmiş, $25^{\circ} \mathrm{C}$ 'de 12 saat aydınlık/12 saat karanlık ortamda 5 gün boyunca belirti gelişimi izlenmiştir. Kontrol uygulamasında ise, sadece $6 \mathrm{~mm}$ çaplı PDA diski yara yerine yerleştirilmiş ve parafilm ile sarılmıştır. Her bir uygulama tesadüf parselleri deneme deseninde 3 tekerrürlü olarak yürütülmüştür. Meyve yüzeyindeki bozulma ve/veya misel gelişimi pozitif olarak değerlendirilmiş ve bu bölgelerden reizolasyon yapılarak Koch postulatları tamamlanmıştır.

\section{Patojen Fungusun Moleküler Tanılanması}

Patojen fungusun tür düzeyinde tanısını yapmak için moleküler sekansı yapılmıştır. Moller et al. (1992) tarafindan hazırlanan protokol kullanılarak patojenin misellerinden genomik DNA'sı izole edilmiştir. Patojen fungusun rDNA'sı kullanılarak ITS bölgesi ITS1-ITS4 primerleri kullanılarak çoğaltılmıştır. Amplifiye edilmiş PCR ürünü sekans için Refgen 
Company Ltd.'e gönderilerek sekans sonucu Genbank'ta depolanmıştır.

\section{In vitro Deneme}

İkili kültür testlerinde $20 \mathrm{ml}$ PDA içeren Petri kapları $(90 \mathrm{~mm})$ kullanılmış, biyoajan bakteri izolatları Nutrient Agar (NA)'da 24 saat, patojen fungus izolat1 ise $P D A$ 'da 5 gün süresince geliştirilmiştir. Daha sonra PDA içeren Petri kaplarının etrafina steril öze ile biyoajan bakteri kültürü çizilmiş, Petri kabının orta kısmına ise $6 \mathrm{~mm}$ fungal disk yerleştirilmiştir. Petri kapları parafilm ile sarılmış ve $27^{\circ} \mathrm{C}$ 'de inkübasyona bırakılmıştır. Kontrol olarak ise Petri kabının ortasına patojen fungusun misel diski yerleştirilmiştir. Kontrol Petrisinde patojen fungus Petri kabının tüm yüzeyini kapladığında fungusun radyal gelişimi mm olarak ölçülerek kaydedilmiştir. Her bir uygulama tesadüf parselleri deneme deseninde 3 tekerrürlü olarak yürütülmüştür. biyoajanın patojen fungus kolonisinin gelişimi yüzde engellenme oranı Mari et al. (1993)'ın belirttiği radyal gelişmenin engelleme yüzdesi formülünden yararlanılarak hesaplanmıştır.

\section{İnhibisyon yüzdesi $(\%)=(C-T) \times 100 /(C-6)$ \\ $\mathrm{C}$ : kontrol petride patojenin çap \\ $\mathrm{T}$ : Bakteri uygulamasında patojenin koloni çapı 6: patojen disk çap1}

Biyoajan fungus izolatlarının etkinliklerinin belirlenmesi amaciyla patojen ve biyoajan funguslar PDA besi ortaminda 3 gün boyunca $27^{\circ} \mathrm{C}$ 'de inkübatörde geliştirilmiştir. Patojen fungus ve biyoajan izolatların kenar kısımlarından alınan 6 mm'lik fungal diskler Skidmore and Dickinson, (1976)'a göre Petri kabına $(90 \mathrm{~mm})$ yerleştirilmiş
(Şekil 1) ve T. harzinum izolatı kontrol Petride tüm yüzeyi kaplayıncaya kadar $27^{\circ} \mathrm{C}^{\prime} \mathrm{de}$ inkübe edilmiştir. Her bir uygulama tesadüf parselleri deneme deseninde 3 tekerrürlü olarak yürütülmüştür. T. harzianum izolatlarının $C$. gloesporoides'e karşı hiperparazitik etkisi yüzde engelleme oranı (\%) formülüne göre hesaplanmıştır (Skidmore and Dickinson, 1976).

YEO $(\%)=\mathrm{R}_{1}-\mathrm{R}_{2} / \mathrm{R} 1 \mathrm{X} 100$

$\mathrm{YEO}=$ Yüzde engelleme oranı (\%)

$\mathrm{R}_{1}=$ Kontrol petrideki patojenin yarıçapı

$\mathrm{R}_{2}=$ İkili kültür petrisindeki patojenin yarıçapı

YEO> 75\%: Çok yüksek düzey etkili $(++++)$

$60 \%<$ YEO $\leq 75 \%$ : Yüksek düzey etkili $(+++)$

$50 \%<$ YEO $\leq 60 \%$ : Orta düzey etkili $(++)$

YEO $\leq 50 \%$ : Düşük düzey etkili $(+)$

Etkisiz (-)
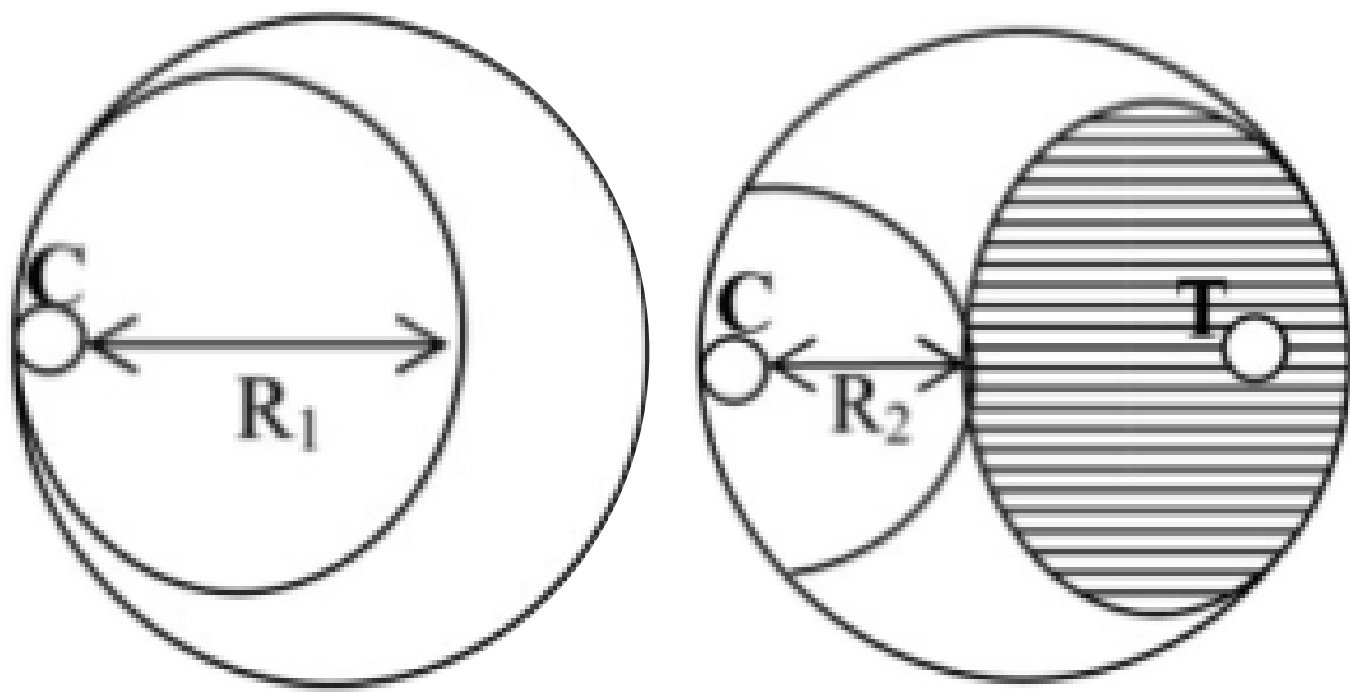

Şekil 1. Patojen ve antagonistik fungus ikili kültür testi uygulaması 


\section{İstatistiki Analiz}

Çalışmada elde edilen tüm verilere açı transformasyonu uygulanmış, JUMP 5.0.1 paket istatistik programı kullanılarak istatistiki analizi yapılmış ve ortalamalar arasındaki farklılıklar LS Means Student testine göre $p<0.01$ önem seviyesinde karşılaştırılmıştır.

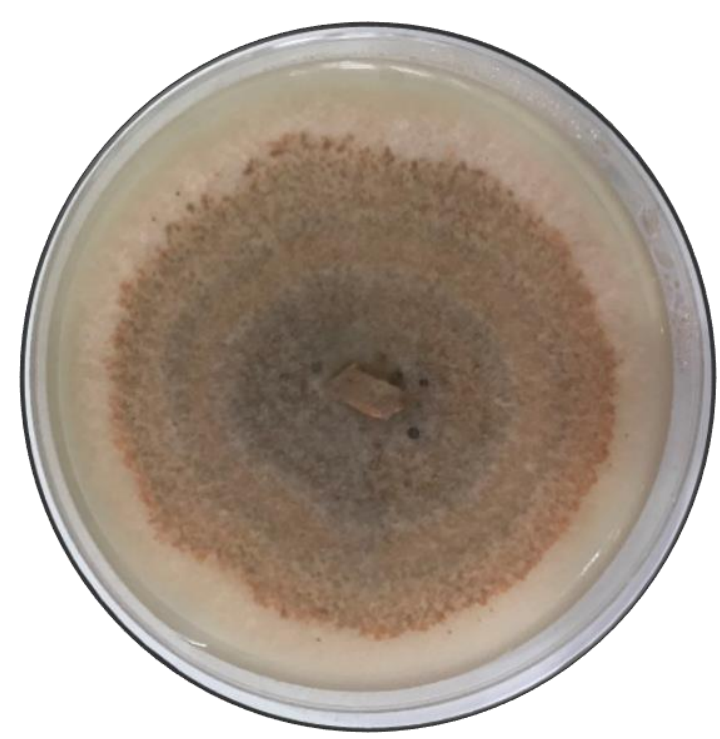

$\mathbf{a}$

\section{BULGULAR VE TARTIŞMA}

C. gloesporoides izolatının PDA besiyerindeki koloni gelişimi ve mikroskobik görüntüsü Şekil 2'de, patojenisite test sonucu Şekil 3'de verilmiş̧ir.

Portakaldan elde edilen fungusun patojenitesi yapılmış ve sonuç pozitif çıkmışıı (Şekil 3).

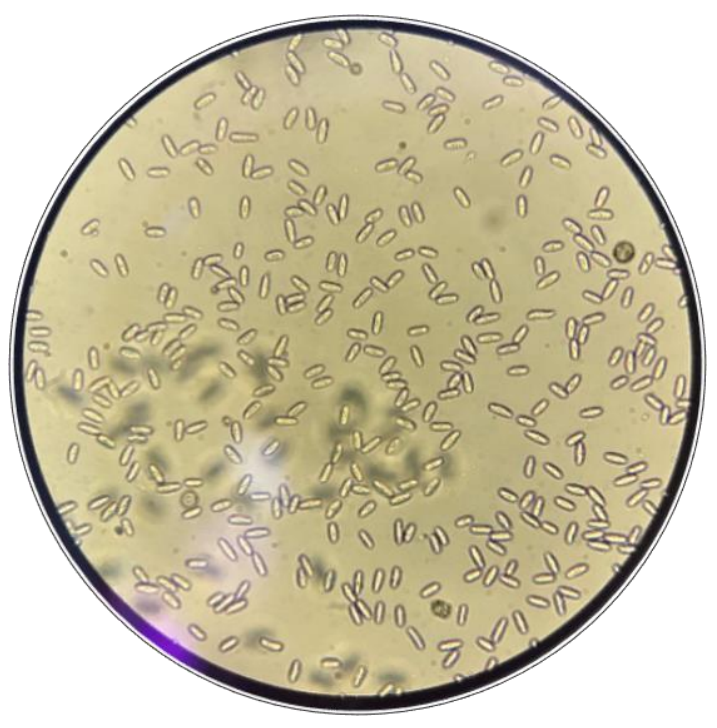

b

Şekil 2. Colletotrichum gloesporoides' in PDA'da gelişimi (a) ve mikroskop görüntüsü (b) (40X)

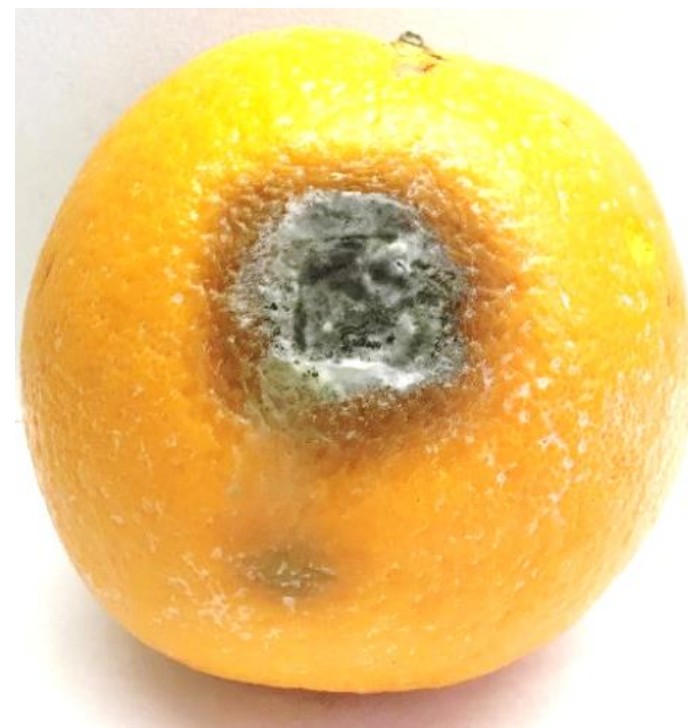

$\mathbf{a}$

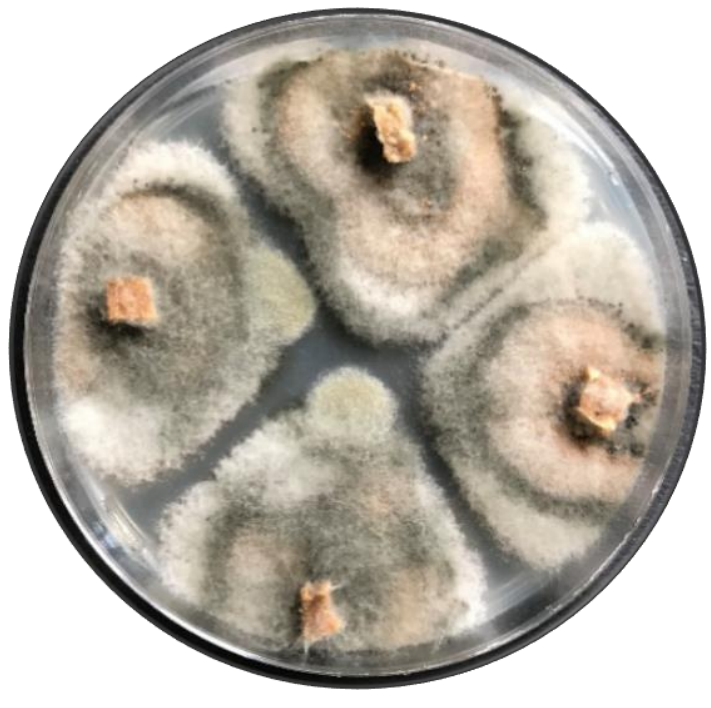

b

Şekil 3. Colletotrichum gloesporoides'in portakal meyvesinde patojenisite testi sonucu (a) ve re-izolasyonu (b) 
Moleküler tanılama sonuçlarına göre patojen fungus izolatı C. gloesporoides olarak \%99,48 benzerlik indeksi ile tanılanmış ve sekans tablosu Çizelge 3'de verilmiştir. Moleküler sekans sonucu
GenBank'a yüklenmiş ve 2153951 erişim numarası verilmiştir. C. gloesporoides izolatına ET 87 kodu verilerek fungus kültür koleksiyonuna eklenmiştir.

Çizelge 3. Patojen fungus Colletotrichum gloesporoides'in sekans tablosu

\begin{tabular}{ll}
\hline 1 & TATAAGCGGGGTATTCCTACCTGATCCGAGGTCACCTTTGGAAAATTGGGCGGGTTTTAC \\
61 & GGCAAGAGTCCCTCCGGATCCCAGTGCGAGACGTAAAGTTACTACGCAAAGGAGGCTCC \\
121 & GTCCGCCACTACCTTTGAGGGCCTACATCGGCTGTAGGGCCCCAACACGGGAGGCAAGC \\
181 & AGAGCTTGAGGGTTGAAATGACGCTCGAACAGGCATGCCCGCCAGAATGCTGGCGGGC \\
241 & GCAATGTGCGTTCAAAGATTCGATGATTCACTGAATTCTGCAATTCACATTACTTATCGC \\
301 & ATTTCGCTGCGTTCTTCATCGATGCCAGAACCAAGAGATCCGTTGTTAAAAGTTTTGATT \\
361 & ATTTGCTTGTACCACTCAGAAGAAACGTCGTTAAATCAGAGTTTGGTTATCCTCCGGCGG \\
421 & GCGCCGACCCGCCCGGAGGCGGGAGGCCGGGAGGGTCGCGGAGACCCTACCCGCCGAA \\
481 & GCAACAGTTGTAGGTATGTTCACAAAGGGTTGTAGAGCGTAAACTCAGTAATGATCCCT \\
541 & CCGCTGGTTCACCAACGGAGACCTTGTTACGACTTTTACTTCCCAAAAAATGAACAAGG \\
601 & AAGGATCT \\
\hline
\end{tabular}

İkili kültür testlerinde $C$. gloesporoides' in ET 87 izolatına karşı test edilen antagonistik bakterilerin antifungal aktivitelerinin sonucu Çizelge 4 'te, en etkili 3 antagonistik bakteriye ait petri görünümleri ise Şekil 4 'te verilmiştir. Bütün antagonistik bakteriler farklı düzeylerde ET 87 izolatının gelişimini engellemişlerdir. Antagonistik bakteri izolatların yüzde engelleme oranları \% 11,90 ile $\% \quad 69,05$ arasında tespit edilmiștir. En yüksek engelleme oranı MF $3(\% 69,05)$ izolatında belirlenirken, bu izolatı TV $6 \mathrm{~F}(\% 62,50)$ ve TV 17C $(61,31)$ izolatları takip etmiștir. En düşük engelleme oranı ise TV 12E $(\% 11,90)$ izolatından elde edilmiştir (Çizelge 4). TV 85D (\%60,71), CP 1 (\%53,57), RK $92(\% 46,43)$, RK $79(\% 42,26)$ ve TV 3D $(\% 15,48)$ 'nin de farklı oranlarda patojenin gelişimini engelledikleri ve hepsinin istatistiki olarak farklı gruplarda yer aldığı tespit edilmiştir. Kontrol uygulamasının yüzde engelleme oranı diğer tüm test edilen antagonistik bakterilerden istatistiki olarak $(\mathrm{p} \leq 0.01)$ farklı bulunmuştur.

Çizelge 4. In vitro' da Colletotrichum gloesporoides'in ET 87 izolatına karşı test edilen antagonistik bakterilerin yüzde engelleme oranları

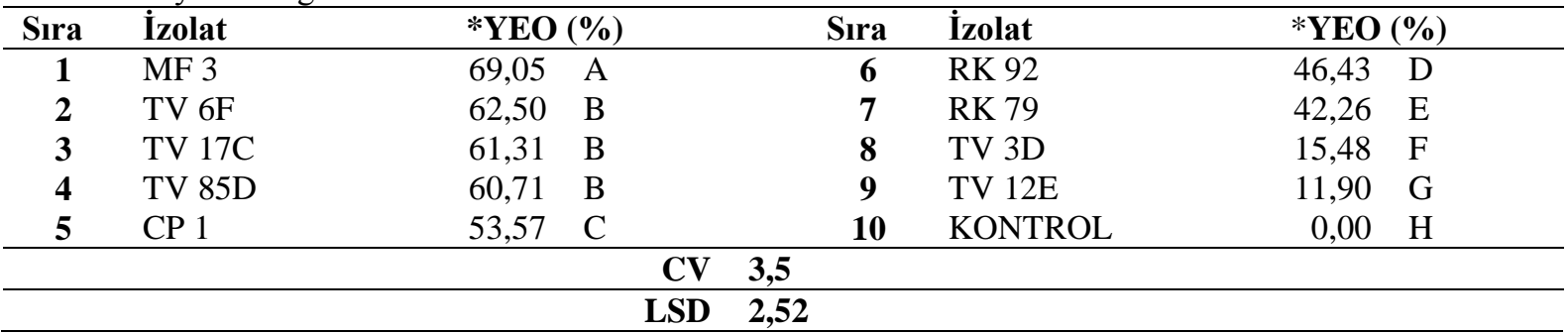

*Aynı sütunda benzer harfle ifade edilen değerler arasında istatistiki açıdan fark yoktur (p<0.01). YEO (\%): Yüzde engelleme oranı 


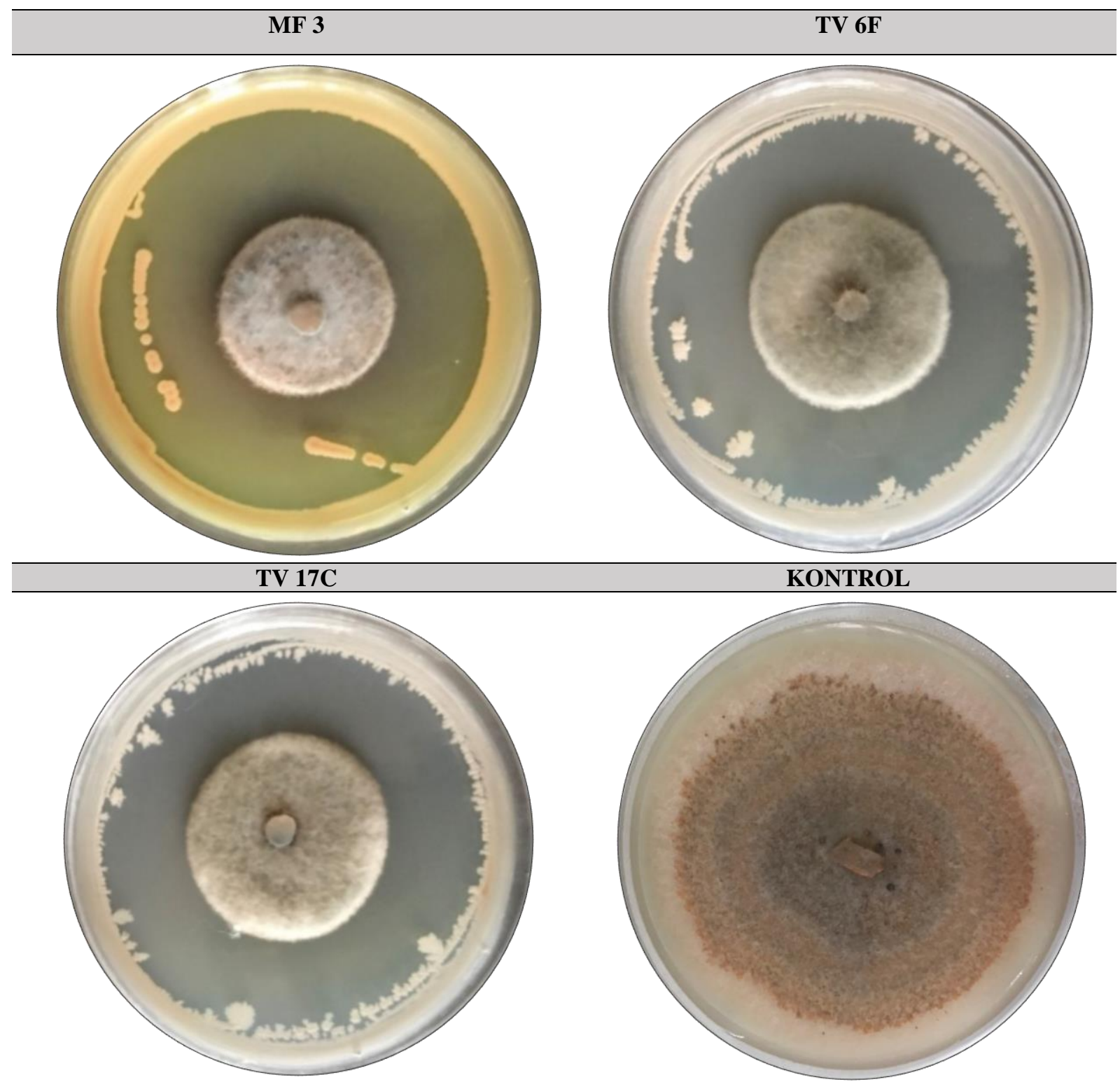

Şekil 4. Colletotrichum gloesporoides'in ET 87 izolatına karşı en yüksek engelleme oranına sahip MF 3, TV 6F ve TV $17 \mathrm{C}$ antagonistik bakteri izolatlarının petrideki görünümleri

C. gloesporoides'in ET 87 izolatına karşı test edilen $T$. harzianum izolatlarının etkinliği in vitro'da test edilmiş ve hiperparazitik etkileri Çizelge 5'te, Petri görünümleri ise Şekil 5'te verilmiştir. Tüm hiperparazitik fungus izolatları farklı düzeylerde etkili bulunmuştur. T. harzianum izolatları içinde en yüksek yüzde engelleme oranı ET $4(\% 82,50)$ izolatında elde edilirken, bunu ET 14 (\%70) ve NT 1 (\%55) izolatları takip etmiştir. Hiperparazitik özelliğe sahip olan $T$. harzianum izolatlarının hiperparazitik düzeylerine bakıldığında ET 4 izolatı çok yüksek düzey, ET 14 izolatı yüksek düzey ve NT 1 izolatı ise orta düzey etkili bulunmuştur (Çizelge 5).

Çizelge 5. Trichoderma harzianum'un Colletotrichum gloesporoides'in ET 87 izolatına karşı in vitro'da hiperparazitik etkisi

\begin{tabular}{lc|c|c|c|c|c}
\hline \multirow{2}{*}{ ET 87 izolatı } & \multicolumn{5}{c}{ Trichoderma harzianum izolatları } \\
\cline { 2 - 7 } & \multicolumn{2}{c}{ ET 4 } & \multicolumn{2}{c}{ ET 14 } & \multicolumn{2}{c}{ NT 1 } \\
\cline { 2 - 7 } & $*$ YEO $(\%)$ & HD & YEO $(\%)$ & HD & $*$ YEO (\%) & HD \\
\hline & 82,50 & ++++ & 70,00 & +++ & 55,00 & ++ \\
\hline
\end{tabular}




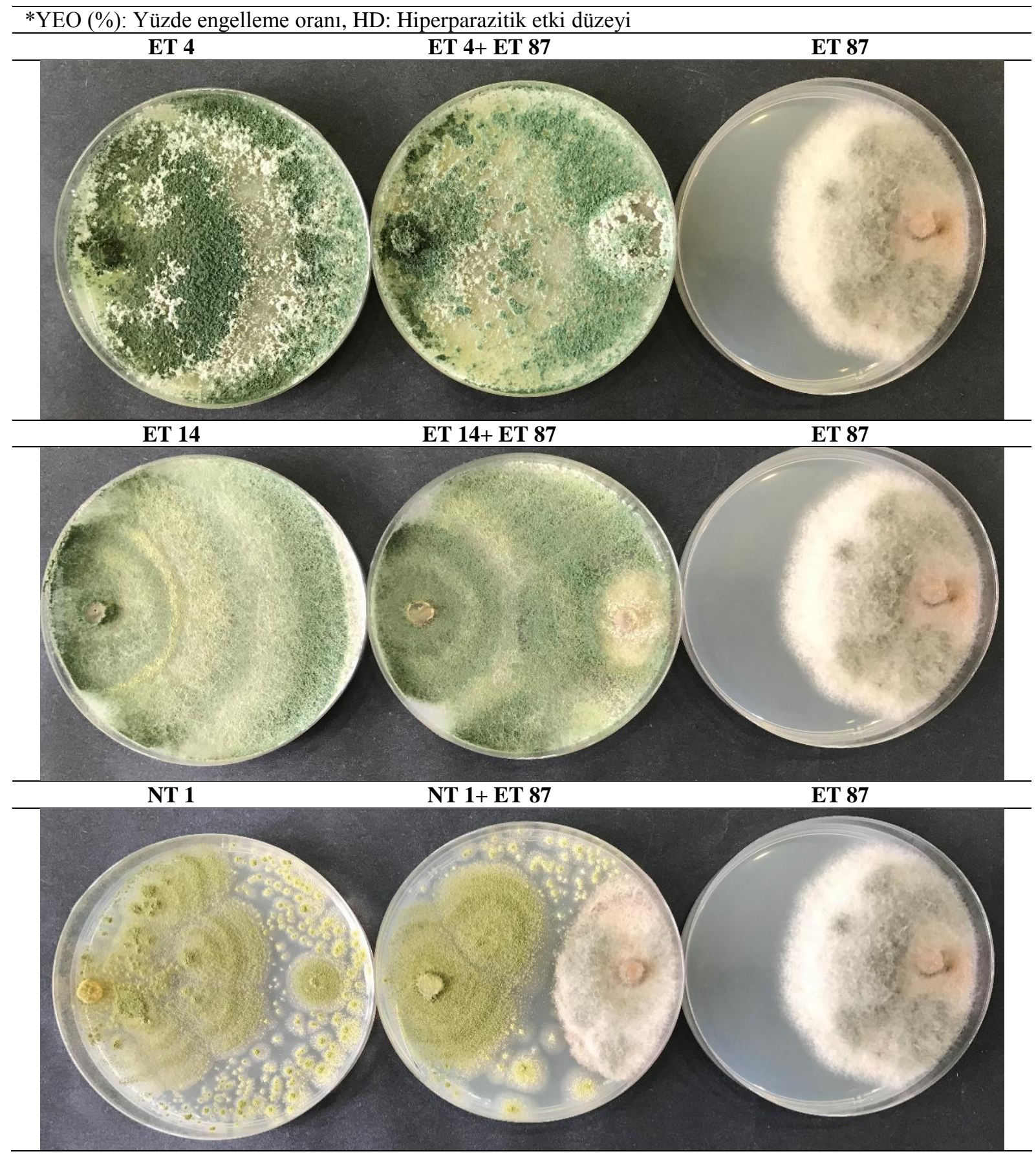

Şekil 5. Colletotrichum gloesporoides'in ET 87 izolatına karşı hiperparazitik T. harzianum izolatlarının Petri görünümleri

Biyolojik mücadele yaklașımı, mikroorganizmalar kullanılarak bitki hastalıklarının çevreye dost bir şekilde kontrolünün sağlandığı etkili bir yöntemdir. Bu yöntemde ilk adım, potansiyel mikrobiyal antagonistlerin belirlenmesi ve in vitro'da patojene karşı etkililiklerinin test edilmesidir. Yapılan birçok çalışmada, fungus ve bakterilerin antagonistik etkilerinin hasat öncesi ve sonrasında ortaya çıkan hastalıkları önlemede başarılı bir şekilde kullanıldı ̆̆ kaydedilmiştir (Kotan vd., 2009; Begum et al., 2010; Tozlu vd., 2016; Tozlu vd., 2018; Tekiner vd., 2018). Ayrıca, bu mikrobiyal antagonistlerin enzim veya antibiotik üreterek, hızlı kolonize olarak, güçlü rekabet ederek ve uyarılmış dayanıklılık ile patojenin 
gelişimini engelledikleri de yapılan bazı çalışmalarda ortaya konulmuştur (Harman, 1993; Wright et al., 2001; Monte, 2001; Kotan vd., 2009).

Bacillus, Pseudomonas, Pantoea, Trichoderma, Metarhizium cinslerine ait birçok izolat biyoajan olarak çeşitli patojenlerin kontrolünde kullanılabilmektedirler. Ayrıca, bu cinslere ait türlerin C. gloesporoides'e karşı potansiyel biyoajan olarak kullanıldığını gösteren birçok çalışma da bulunmaktadır (Bautista-Banos et al., 2003; Rahman et al., 2007; Ashwini and Srividya, 2014). Bu çalışmada da daha önce yapılan çalışmalarda farklı patojenlere karşı başarılı bulunan bakteri ve fungusların etkililiği C. gloesporoides'a karşı test edilmiş ve in vitro'dapatojen fungusun gelişimini farklı düzeylerde engelledikleri görülmüştür.

Antagonistik mikroorganizmalar içerisinde toprak, su ve bitki yüzey ortamlarına kolonize olabilen, patojenik olmayan saprofit bakteri türlerini içeren Pseudomonas cinsi. içerisinde yer alan Pseudomonas fluorescens ise funguslar ve bakteriler tarafından oluşturulan hastalıkları önemli ölçüde kontrol edebilmektedirler (Hubbard et al., 1983; Erdoğan ve Benlioğlu, 2010; Şenol, 2014; Tozlu, 2016). Ayrıca, bu bakteri türünün hem tek başına hem de fungisitlerle birlikte verildiğinde hastalıkları baskılamada etkili olduğu ortaya konulmuş, ürün verimi üzerine de olumlu etki yaptığı bildirilmiştir (Ganeshan and Kumar 2005). Yine yapilan çalışmalarda, $P$. fluorescens'in patojenin gelişimini üretmiş olduğu antibiotik benzeri maddeler ile engellediği belirlenmiştir (Clarkson and Lucas, 1997; Hass and Defago, 2005; Güneş vd., 2015). Bu çalışmada da $P$. fluorescens' in MF 3 izolatı en etkili sonucu vermiştir.

Bacillus türleri çalışmada etkili olan diğer bakteriyel antagonistlerdir. Bacillus'larher yerde bulunabilen, kolonizasyon yeteneği yüksek ve endospor oluşturan önemli bir cinstir (Arrebola et al., 2010). Sahip oldukları bu özellikler diğer antagonistlere göre uygulamada başarı şansını arttırarak büyük avantaj sağlamaktadır. Bacillus cinsi içerisinde ise $B$. substilis türünün iyi bir biyoajan olabileceği farklı araştırmacılar tarafından vurgulanmıştır (Jiang et al., 2001; Zhang and Dou, 2002; Yang et al., 2006; Kotan et al., 2009; Wang et al., 2010; Zhao et al., 2011). Bu çalışmada da in vitro'da etkili olan ilk beş bakteriden dördü Bacillus cinsine ait izolatlardan (B. subtilis TV 6F, TV 17C, CP 1; B. cereus TV 85D) oluşmaktadır.

Hiperparazitik özelliğe sahip funguslar içerisinde yer alan Trichoderma (Sivan and Chet, 1986) cinsine ait izolatların da farklı bitki patojenlerine karşı etkili bir şekilde kullanıldığ araştırıcılar tarafindan belirlenmiştir (Santamarina and Roselló, 2006; Shi et al., 2012; Kumar et al., 2015). Hasat sonrası patojenlerin kontrolünde $T$. harzianum'un etki şeklinin ise doğrudan patojeni parazitlemesinden ve bazı enzimleri üretmesinden dolayı olduğu ortaya konulmuştur. Bunlardan kitinolitik enzimler, patojen fungusun hücre duvarındaki kitinin yapısını bozabildiklerinden dolayı hasat sonras1 patojenlerin biyolojik kontrolünde önemli bir yere sahiptirler (Sid Ahmed et al., 2003). Bu çalışmada da kullanılan T. harżianum izolatlarının daha önce yapılan çalışmalarda kitin enzimi ürettiklerinin belirlenmiş olması (Tozlu vd., 2018) bu ümitvar biyoajanların patojenin gelişimini bu şekilde engellediğini düşündürmektedir.

Sonuç olarak, MF 3 ve ET 4 izolatlarının portakal meyvesinde antraknoza neden olan $C$. gloesporoides'in in vitro'da kontrolü için kullanılabileceği tespit edilmiştir. Ayrıca, etkili olan antagonistik mikroorganizmaların farklı sicaklık ve nem değerlerine sahip olan depo koşullarında da test edilmesi büyük önem arz etmektedir. Bundan sonraki çalışmalar bu yönde planlanıp yürütülmeye çalışılacaktır.

\section{KAYNAKLAR}

Akgün, C., 2006. Turunçgiller Sektör Profili. Dış Ticaret Servisi Uygulama Şubesi, Türkiye: (http:///20684676Turuncgillersektorprofili.html) (Erişim Tarihi: 10 Mart 2019).

Aloui, H., Khwaldia, K., Licciardello, F., Mazzaglia, A., Muratore, G., Hamdi, M., 2014. Efficacy of the combined application of chitosan and locust bean gum with different citrus essential oils to control postharvest spoilage caused by Aspergillus flavus in dates. International Journal of Food Microbiology, 170: 21-28.

Ashwini, N., Srividya, S., 2014. Potentiality of Bacillus subtilis as biocontrol agent for management of anthracnose disease of chilli caused by Colletotrichum gloeosporioides OGC1. 3 Biotech, 4 (2): 127-136.|

Bautista-Banos, S., Hernandez-Lopez, M., BosquezMolina, E., Wilson, C.L., 2003. Effects of chitosan and plant extracts on growth of Colletotrichum gloeosporioides, anthracnose levels and quality of papaya fruit. Crop Protection, 22: 1087-1092.

Begum, M.F., Rahman, M.A., Alam, M.F., 2010. Biological control of Alternaria fruit rot of chili by Trichoderma species under field conditions. Mycobiology, 38 (2): 113-117.

Benli, M., 2003. Hasat sonrası fungal hastalıklarla kimyasal ve biyolojik mücadele. Orlab On Line Mikrobiyoloji Dergisi, 01 (08): 1-25.

Clarkson, J.P., Lucas J.A., 1997. The role of antibiotic production by a strain of Pseudomonas fluorescens in the suppression of Pseudocercosporella herpotrichoides, the causal 
agent of eyespot disease of cereals. Journal of Applied Microbiology, 82: 499-506.

Dubey, N., Srivastava, B., Kumar, A., 2008. Current status of plant products as botanical pesticides in storage pest management. Journal Biopesticide, 1 (2): 182-186.

Ekinci, M., Turan, M., Yıldırım, E., Güneş, A., Kotan, R., Dursun, A., 2014. Effect of plant growth promoting rhizobacteria on growth, nutrient, organic acid, amino acid and hormone content of cauliflower (Brassica oleracea L. var. botrytis) transplants. Acta Scientiarum Polonorum, 13 (6): 71-85.

Ekinci, M., Yıldırım, E., Kotan, R., 2015. Effects of different plant growth promoting rhizobacteria on growth and quality of broccoli (Brassica oleraceae L. var. italica) seedling. Akdeniz University Journal of Agriculture, 28 (2): 53-59.

Erdoğan, O., Benlioğlu, K., 2010. Biological control of Verticillium wilt on cotton by the use of fluorescent Pseudomonas spp. Biological Control, 53 (1): 39-45.

Erman, M., Kotan, R., Çakmakçı, R., Çı̆̆, F., Karagöz, K., Sezen, M. 2010. Effect of nitrogen fixing and phosphate-solubilizing rhizobacteria isolated from Van Lake Basin on the growth and quality properties in wheat and sugar beet. Turkey IV. Organic Farming Symposium, 28 June - 1 July 2010, Erzurum, Turkey, s: 325-329.

FAO, 2017. Food and Agriculture Organisation of the United Nations, FAOSTAT Agriculture Data. Rome, Italy:. (http://faostat.fao.org) (Erişim Tarihi: 10 Mart 2019).

Ganeshan, G., Kumar M.A., 2005. Pseudomonas fluorescens, a potential bacterial antagonist to control plant diseases, Journal of Plant Interactions, 1 (3): 123-134.

Güneş, A., Karagöz, K., Turan, M., Kotan, R., Yıldırım, E., Çakmakçı, R., Şahin F., 2015. Fertilizer effiency of some plant growth promoting rhizobacteria for plant growth. Research Journal of Soil Biology, 7 (2): 28-45.

Harman, G., 1993. Chitinolytic Enzymes of Trichoderma harzianum: purification of chitobiosidase and endochitinase. Phytopathology, 83 (3): 313.

Hass, D., Defago, G., 2005. Biological control of soil born pathogens by fluorescent Pseudomonads. Nature Reviews Microbiology, 3: 307-319.

Hubbard, J., Harman, G., Hadar, Y., 1983. Effect of soilborne Pseudomonas spp. on the biological control agent. Trichoderma hamatum, on pea seeds. Ecology and Epidemiology, 73 (5): 655659.

Karaçalı, İ., 1993. Bahçe ürünlerinin muhafaza ve pazarlanması. Ege Üniversitesi yayınları, İzmir, $494 \mathrm{~s}$.
Karakurt, H., Kotan, R., Aslantaş, R., Dadaşoğlu, F., Karagöz, K., Şahin, F., 2010. Bitki büyümesini teşvik eden bazı bakteri strainlerinin 'şekerpare' kayısı çöğürlerinin bitki gelişimi üzerine etkileri. Atatürk Üniv. Ziraat Fak., Derg., 41 (1): 7-12.

Kotan, R., Şahin F., Demirci E., Eken, C., 2009. Biological control of the potato dry rot caused by Fusarium species using PGPR strains. Biological Control, 50: 194-198.

Kumar, V., Neeraj, Sharma, S., Sagar, N.A. 2015. Post Harvest Management of Fungal Diseases in Onion - A Review. International Journal of Current Microbiology and Applied Sciences, 4: 737-752.

Mahoney, M.J., Tattar, T.A, 1980. Identification, etiology and control of Euonymus fortunei anthracnose caused by Colletotrichum gloeosporioides. Plant Dis., 64: 854-856.

Mari, M., Iori, R., Leoni, O., Marchi, A., 1993. In vitro activitiy of glucosinolate-derived isothiocyanates against postharvest fruit pathogens. Annals of Applied Biology, 123: 155164.

Moller, E.M., Bahnweg, G., Sandermann, H., Geiger, H.H., 1992. A simple and efficient protocol for isolation of high molecular weight DNA from filamentous fungi, fruit bodies and infected plant tissues. Nucleic Acids Research, 20 (22): 61156116.

Monte, E., 2001. Understanding Trichoderma: between biotechnology and microbial ecology. International Journal of Microbiology, 4: 1-4.

Ongena, M., Jacques, P., 2008. Bacillus lipopeptides: versatile weapons for plant disease biocontrol. Trends in Microbiolilogy, 16 (3): 115-125.

Rahman, M.A., Kadir, J.T., Mahmud, M.M., Abdul Rahman, R., Begum, M.M., 2007. Screening of antagonistic bacteria for biocontrol activities on Colletotrichum gloeosporioides in papaya. Asian Journal of Plant Sciences, 6: 12-20.

Santamarina, M.P., Roselló, J., 2006. Influence of temperature and water activity on the antagonism of Trichoderma harzianum to Verticillium and Rhizoctonia. Crop Protection, 25: 1130-1134.

Shi, M., Chen, L., Wang, X.W., Zhang, T., Zhao, P.B., Song, X.Y., Sun, C.Y., Chen, X.-L., Zhou, B.C., Zhang, Y.Z. 2012. Antimicrobial peptaibols from Trichoderma pseudokoningii induce programmed cell death in plant fungal pathogens. Microbiology, 158: 166-175.

Sid Ahmed, A., Ezziyyani, M., Perez Sanchez, C., Candela, M.E., 2003. Effect of chitin on biological control activity of Bacillus spp. and Trichoderma harzianum against root rot disease in pepper (Capsicum annuum) plants. European Journal of Plant Pathology, 109: 633-637. 
Singh, D., Sharma, R.R., 2007. Postharvest diseases of fruit and vegetables and their management. In: Prasad, D. (Ed.), Sustainable Pest Management. Data Publishing House, New Delhi, India.

Sivan, A., Chet, I., 1986. Biological control of Fusarium spp. in cotton, wheat and muskmelon by Trichoderma harzianum. Journal Phytopathology, 116 (1): 39-47.

Skidmore, A.M., Dickinson, C.M., 1976. Colony interactions and hyphal interference between Septoria nodorum and Phylloplane fungi. Transactions of the British Mycological Society, 66: $57-64$.

Şenol, M., 2014. Pseudomonas fluorescens ve Bacillus subtilis bakterilerinin Fusarium culmorum'a karşı antifungal etkinliği, bakterilerden elde edilen kitinaz enziminin saflaştırılması ve bazı kinetik özelliklerinin belirlenmesi, Atatürk Üniversitesi Fen Bilimleri Enstitüsü, Yüksek Lisans Tezi, 64 s.

Talibi, I., Boubaker, H., Boudyach, E.H., Aoumar, A.A.B., 2014. Alternativa methods for the control of postharvest citrus diseases. J. Appl. Microbiol., 117: 1-17.

Tekiner, N., Tozlu, E., Kotan, R., Dadasoğlu, F., 2018. Biological control of Botrytis cinerea and Alternaria alternata with bioagent bacteria and fungi under in vitro conditions. Conference: 2 nd International professional and technical sciences congress (UMTEB) 10-13 May, 2018, Batum/Gürcistan, p 97.

Than, P.P, Jeewon, R., Hyde, K.D., Pongsupasamit, S., Mongkolporn, O., Taylor, P.W.J. Characterization and pathogenicity of Colletotrichum species associated with anthracnose disease on chilli (Capsicum spp.) in Thailand. Plant Pathology, 57: 562-572.

Tozlu, E., 2016. Bazı bakteriyel biyokontrol ajanlar ile havuç acı çürüklük hastalığı (Geotrichum candidum Link)'nın biyolojik mücadelesi. Atatürk Üniv., Ziraat Fak. Derg., 47 (1): 1-9.
Tozlu, E., Tekiner, N., Tozlu, G., Kotan, R., Çalmaşur, Ö., Göktürk, T., Dadaşoğlu, F., 2018a Icerya purchasi Maskell, 1878 (Hemiptera: Margarodidae)'nin Entomopatojen Fungus ve Bakterilerle Biyolojik Mücadelesinin Araştırılması. Conference: III. Türkiye Orman Entomolojisi ve Patolojisi Sempozyumu, 10-12 Mayıs 2018, Artvin, Türkiye, s: 43.

Tozlu, E., Tekiner, N., Kotan, R., 2018b. Screening of Trichoderma harzianum Rifai (1969) isolates of domestic plant origin against different fungal plant pathogens for use as biopesticide. Fresenius Environmental Bulletin, 27 (6): 42324238.

TÜİK, 2017. Türkiye İstatistik Kurumu (www.tuik.gov.tr) (Erişim Tarihi: 10 Mart 2019).

Wright, S.A., Zumoff, C.H., Schneider, L., Beer, S.V., 2001. Pantoea agglomerans strain Eh318 produces two antibiotics that inhibit Erwinia amylovora in vitro. Applied and Environmental Microbiology, 67: 284-292.

Yamamoto, S., Shiraishi, S., Suzuki, S., 2014. Are cyclic lipopeptides produced by Bacillus amyloliquefaciens S13-3 responsible for the plant defence response in strawberry against Colletotrichum gloeosporioides. Letters in Applied Microbiology, 60: 379-386.

Zhang, J.X., Timmer, L.W., 2007. Preharvest application of fungicides for postharvest disease control on early season tangerine hybrids in Florida. Crop Protection, 26: 886-893.

Zhou, Y., Zhang, L., Zeng K., 2016. Efficacy of Pichia membranaefaciens combined with chitosan against Colletotrichum gloeosporioides in citrus fruits and possible modes of action. Biological Control, 96: 39-47. 